\title{
Cantonese with an Accent" Identity and Symbolic Power in Guangdong
}

\author{
Wang Wei \\ Chengdu Institute of Public Administration, China \\ nonstopfly@qq.com
}

Keywords: Cantonese, Language identity, Symbolic power.

\begin{abstract}
The purpose of this paper is to study the role of Cantonese in the identity reconstruction process of migrant people, and its relationship with symbolic power. To aid my analysis, I conducted 22 open-ended interviews; most of the subjects were migrant people who came from remote areas. Their experience showed that during their adaptation process, Cantonese works as a symbolic mark to distinguish speakers' identity and influences their social and economic positions.
\end{abstract}

\section{Introduction}

During with the reform and opening up of China, the eastern coastal areas have led the economic growth, especially in the Pearl River Delta region including Shenzhen, Dongguan, and Guangzhou. These cities contribute greatly to the world manufacturing industry and are famous for low-priced products. Because of the low cost of labor, convenient transportation, and government support, these places attract plenty of investment and are home to more factories than inland cities. The region has become a dreamland for rural migrant people, especially those from the underdeveloped central and western rural areas, as a place where they can make more money and broaden their minds. Guangdong, for example, as the exemplar of China's reform and opening up, has undergone rapid economic growth fueled by the manufacturing industry. According to the 2016 census, there were about 32,020,000 migrant people in Guangdong province, or 29.5 percent of the total population of the province. This is an increase of 15,274,900 migrant people since 2000, and represents about 60 percent more growth than the local population growth.

Cantonese is one of the most common dialects in the Pearl River Delta region and is quite important to the people who live there. Although Mandarin is the official language in most Chinese cities, it is still not as popular as Cantonese in this area. Especially for migrant people, Cantonese is one the best ways to adjust to local life. If they cannot speak Cantonese, their job choices are quite limited, especially for the illiterate and unskilled. Their options are limited to less honorable occupations such as cleaner, babysitter, or factory worker. If they cannot speak Cantonese, they might be paid less than the locals. Without Cantonese, their social relations may be so limited that they cannot take part even in basic social activities. Without Cantonese, they cannot receive equal respect from local people, even when they have a local ID. Without Cantonese, their identity will always be defined as migrant people. In order to find more job opportunities, friends, and respect, many of them choose to learn Cantonese, even though it is quite difficult.

To some extent, Cantonese plays a dominant role in this area. It impacts their daily life, and it constrains their identity. More than simply a tool for communication, it marks identity and distinguishes people from different social groups.

\section{Literature Review}

2.1Language and Identity From Piller's (2011) perspective, a particular language matches a particular culture. Different places have different cultures, and language is one of the most obvious characteristics to represent a particular culture. When individuals speak a language, they are not only choosing a dialect to use, but also demonstrating their cultural belonging. Individuals who share the same culture are more likely to treat each other as "us" or as members of the same group. If those people are not speaking the same language, they are more likely to be treated as "others" and be 
excluded from their group, because they do not share the same culture. To some degree, language plays a gatekeeper role during encounters to distinguish who should belong inside and who should belong outside. The inside people often share the same culture and keep loyal to their group, while outside people often struggle with the culture and language differences in order to be accepted.

Language constrains individuals' identities, and linguistic proficiencies are quite important to the identity construction process. To some degree, different languages offer different ways for us to experience and perceive the world around us. This means that when individuals are talking about the same things, they will perform totally different identities. In addition, when a person's linguistic proficiencies have been changed, his/her identity will be changed at the same time. This is to say that if people wish to change or rebuild their identities, they should acquire more linguistic proficiencies. The more linguistic proficiencies they have, the more identities they can choose to perform (Piller, 2011).

2.2Language and Symbolic Power From Bourdieu's (1986) perspective, individuals' social status is based on the possession of field-relevant capital, which can be divided into four categories: economic, social, cultural, and symbolic (prestige, status, and reputation). Together economic, social, cultural, and symbolic value become worth more than the material properties of the capital, to attract proposals. The level and combinations of different kinds of capital that an individual possesses determines his or her status in a particular field. Their influence on other individuals, and whether they dominate or are dominated, is their symbolic capital. Symbolic capital is a special category. From the system of recognition and legitimization of power, in some cases, it can exchange with cultural, economic, and social capital. As for the characteristics of the field or in a particular social background, language as a form of embodied cultural capital can be transformed into other forms of capital as symbolic capital.

Symbolic capital can produce changes in social position. Society is divided into classes. Accent, grammar, and vocabulary variations have become marks for language users. Even the most basic exchange between two speakers will reflect the social structure that they are part of and which their words help to reproduce. If a speaker possesses more linguistic capital than others, he or she is more likely to make use of the system to his or her advantage and get more benefits of distinction. In the material world, symbolic profits do not directly correspond to the cost of the formation of speakers. It depends on the language products distributed by virtue of their position in the structure of the market with all kinds of scarcity value. In this model, people who can realize the most value and ensure maximum profit also help to build and maintain the structure (Bourdieu, 1991).

Language works in a symbolic violence system. According to Bourdieu (1991), symbolic violence is a gentle, invisible form of violence that operates within the culture and also in the hierarchies of language and language users. Every expression is the product of reconciliation between an "expressive interest" and the censorship in the social architecture. Speakers will choose a certain form that is positively authorized by the social structure. People in different situations will suffer different forms of symbolic violence; the more formal the situation, the more obvious violence the speakers will suffer, especially when they are not used to the dominant language.

\section{Research Questions}

RQ1: What are the driving forces that push migrant people to learn Cantonese in Guangdong?

RQ2: What kinds of power relations exist within the context of Cantonese in Guangdong?

\section{Methodology}

The open-ended interview is chosen to find answers to the research questions. My main focus is to study the immigrants' experience and their ideas about Cantonese. Therefore, most of my interviewees are migrant people. The majority of these migrant people came from rural areas that are not as rich and developed as Guangdong. I also invited eight local people to do interviews because their cultural backgrounds are quite different from the migrants and can provide a more comprehensive view to evaluate Cantonese. 
Table 1. Background of the 22 interviewees.

\begin{tabular}{|c|c|c|c|c|c|c|}
\hline Name & Gender & Hometown & Occupation & $\begin{array}{l}\text { Education } \\
\text { level }\end{array}$ & Income & $\begin{array}{l}\text { Years in } \\
\text { Zhuhai }\end{array}$ \\
\hline $\mathrm{Xu}$ & Male & Henan & Worker & Primary school & Y 2500 & 5 \\
\hline Zhang & Female. & Henan & Clerk & Primary school & Y 2500 & 4 \\
\hline Wei & Male & Jiangxi & Student & College & $Y 0$ & 3 \\
\hline Zhan & Female & Hainan & Waiter & Primary school & Y 2200 & 3 \\
\hline Chen & Male. & Sichuan & Student & College & $¥ 0$ & 2 \\
\hline Qin & Female & Hunan & Manager & College & $¥ 4500$ & 10 \\
\hline Xie & Female & Fujian & Student & College & $¥ 0$ & 2 \\
\hline $\mathrm{Li}$ & Female & Sichuan & Manager & High school & $¥ 3500$ & 7 \\
\hline Wang & Male & Xinjiang & Staff & College & $¥ 4500$ & 6 \\
\hline $\mathrm{Cao}$ & Female & Jiangxi & Worker & Primary school & $¥ 2500$ & 9 \\
\hline $\mathrm{Su}$ & Female & Guizhou & Saleslady & Primary school & $¥ 2500$ & 8 \\
\hline Liu & Female & Anhui & Clerk & Middle school & $¥ 3000$ & 4 \\
\hline Gong & Male. & Liaoning & Consultant & High school & Y3500 & 5 \\
\hline Zhou & Female & Shandong & Bank cashier & College & Y 5500 & 6 \\
\hline Wen & Male & Guangdong & Consultant & College & $¥ 3500$ & 28 \\
\hline Xiong & Male & Guangdong & Security & Middle school & $¥ 3500$ & 35 \\
\hline Luo & Female & Guangdong & Consultant & College & $¥ 4500$ & 33 \\
\hline Feng & Female & Guangdong & Commissioner & College & $¥ 4500$ & 31 \\
\hline Wang & Female & Guangdong & Conductor & Middle school & $¥ 4000$ & 28 \\
\hline $\mathrm{Li}$ & Male & Guangdong & Waiter & High school & $¥ 3500$ & 24 \\
\hline Yan & Female. & Guangdong & Saleslady & Middle school & Y3500 & 37 \\
\hline $\mathrm{Li}$ & Female & Guangdong & Training manager & College & $¥ 4000$ & 24 \\
\hline
\end{tabular}

\section{Conclusion and Discussion}

These interviews revealed that Cantonese plays a vital role in migrant people's identity reconstruction process. If migrants want to assume the local identity, they must learn Cantonese. Cantonese is not only a tool for communication, but is also a symbol of social identity in this place.

We can also clearly see the special relationship between Cantonese and symbolic power. Not all dialects are equal in this field; Cantonese is always valued more than other dialects, because to some extent, it can reflect speakers' social and economic positions. The locals use Cantonese to classify people. In this field, Cantonese is playing the dominant role.

I would like to borrow Tsuda's English language pyramid concept to analyze the social classes surrounding Cantonese (Tsuda, 2010, p.257).In this pyramid, Cantonese is under a specific field and special examples are excluded. This creation of social class division works for the majority of migrant people, but does not apply in certain extreme situations.

We can also clearly see the special relationship between Cantonese and symbolic power in Guangdong. Not all dialects are treated equally in this field; Cantonese is always valued more than other dialects, because to some extent, it can reflect speakers' social and economic positions. The locals use Cantonese to classify different people. In this field, Cantonese is playing the dominant role.

As cantonese is part of Cantonese culture, the ability to speak Cantonese is a very important tool for evaluation. There is an incredible gap between Cantonese-speaking people and non-speakers. The special status of Cantonese has created a local class society in which Cantonese native speakers often possess the highest Cantonese abilities. They can participate fully in local communication.

Next are speakers of Cantonese as a second language. In the Cantonese-based class system, they represent quite a large middle class in Guangdong. Therefore, they have the second strongest powers of communication. Most of these people are migrants, like women who married local men, workers in specialized industry, and students. They continue to work hard to improve their Cantonese ability. Some of them may speak with an accent, but their communication is almost equal to native speakers. 
They are also participating well in local activities and are devoted to becoming equal with the local people.

Figure 1 Cantonese-based class system.CSL $=$ Cantonese as a second language

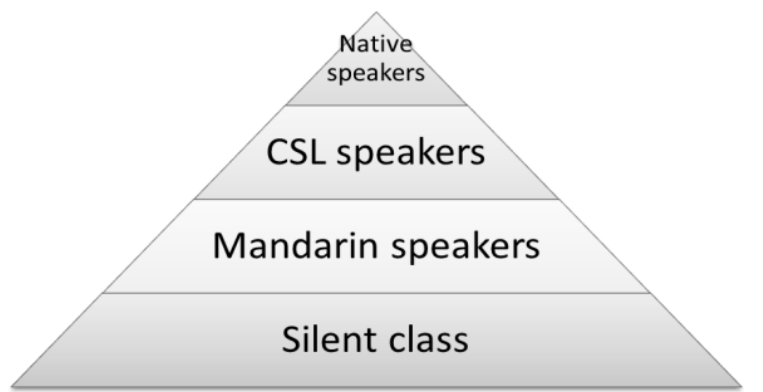

The next level is the people who speak Mandarin. Most of them are migrants trying to make a living in Guangdong. They exist in the working class of the Cantonese-based class system. Some of them successfully learn Cantonese and become CSL speakers. Some of them struggle to learn Cantonese for many years, even for a lifetime, but still fail, so they continue speaking Mandarin. They do not have as much power in communication as native speakers or speakers of Cantonese as a second language. Their participation in local activities is highly restricted and they are easily discriminated against or treated unequally.

At the bottom of this class system are the people who I call the silent class, those who have little or no contact with Cantonese. Most of them are migrant workers who come from rural areas without basic education and cannot speak Mandarin. They speak their mother tongue, and some of their dialects are never heard by others besides their fellow villagers. They usually work as cleaners, factory workers, security guards, and babysitters. They take the jobs that local people never want. Their work is hard, dirty, and risky, but their salary is very low. Local people always look down on them and their participation in local communication is very constrained. Some of them live silently on the margins in the city.

\section{References}

[1] I. Piller, Intercultural communication a critical introduction. Edinburgh : Edinburgh University Press. pp. 57-86, 2011.

[2] P. Bourdieu, The forms of capital. Handbook of Theory and Research for the Sociology of Education. New York: Green wood Press, pp. 241-258, 1986.

[3] P. Bourdieu, Language and symbolic power. Cambridge: Polity Press, pp. 65-92, 1991.

[4] Y. Tsuda, Speaking against the hegemony of English problems, ideologies, and solutions. The Handbook of Critical Intercultural Communication. Oxford: Blackwell Press, pp. 254-262, 2010. 